\title{
Genetic Diversity in Cluster Bean [Cyamopsis tetragonoloba (L.) Taub.] for Morphological Characters
}

\author{
Vikas Kumar*, R. B. Ram and Ram Kumar Yadav \\ Department of Applied Plant Science (Horticulture), School for Bioscience and Biotechnology, \\ Babasaheb Bhimrao Ambedkar University, Vidya-Vihar, Rae-Bareli Road, \\ Lucknow, U.P.-226025, India; vs1744@gmail.com
}

\begin{abstract}
Thirty genotypes of cluster bean [Cyamopsis tetragonoloba (L.) Taub.] were assessed for genetic divergence using Mahalanobis $\mathrm{D}^{2}$ technique. These exhibited wide ranges of genetic diversity for all the characters and grouped into 5 different clusters. The maximum intra cluster distance was observed in cluster I indicated that genotypes under this group are diverse. Based on $\mathrm{D}^{2}$ values, 30 genotypes were classified into five clusters. Maximum inter- cluster distance was between cluster I and cluster II and intra-cluster distance in cluster III, indicating the presence of genetic diversity among the genotypes between the cluster bean. The percent contribution towards genetic diversity was highest from days to maturity (37.87\%) followed by pod yield (q/ha) (22.32\%) and seed yield /plant (g). On the basis of inter-cluster distances and per cent performance observed in the present study, a hybridization programme involving genotypes for a specific character may be selected using cluster mean values.
\end{abstract}

Keywords: Cluster Bean, Clusters Distance, D² Technique, Genetic Divergence

\section{Introduction}

Cluster bean [Cyamopsis tetragonoloba (L.) Taub.] $(2 \mathrm{n}=$ 14) is a versatile and multipurpose legume crop of arid and semiarid regions cultivated for feed, fodder and manure. Cluster bean enhances soil productiveness by fixing atmospheric nitrogen for its own necessitates and also for the succeeding crop. Although cluster bean is a minor crop but due to its better and finer guar gum qualities it is considered as an important cash crop for industrial gum production $^{4,9}$. This is a drought tolerant annual legume crop. It is an important legume crop whose cultivation is mainly concentrated in marginal and sub marginal soils receiving low rainfall. In India, cluster bean occupies an area of 2.20 million hectares with a production of 0.60 million tons ${ }^{11}$.
In North Indian states like Rajasthan, Haryana, Gujarat and Punjab it is mainly cultivated for guar gum production and for forage, whereas in South India it is being cultivated for vegetable purpose. In Karnataka it is being grown in limited area and is cultivated mainly in northern districts like Dharwad, Belgaum, Bijapur, Haveri etc. for tender vegetable pods and it is cultivated year round. Guar is mainly cultivated for food, feed and fodder. It improves fertility of soil by fixing considerable amount of atmospheric nitrogen and adding organic matter.

Genetic diversity is an important factor and also a pre-requisite in any hybridization programme. Inclusion of diverse parents in hybridization programme serves the purpose of producing desirable recombinants. Therefore, an attempt has been made in the present investigation to

${ }^{*}$ Author for correspondence 
estimate genetic divergence among a set of 30 genotypes including for 19 biometrical traits.

The determination of genetic diversity of germplasm will maximize the probability of transgressive segregation and increase the probability that unrelated accessions contribute with positive alleles at different loci. Among various tools available for assessing the genetic variability and relatedness among crop genetic resources, morphological characterization is the first step in the description and organization of germplasm of any crop. In the recent past efforts have been made to assess the genetic diversity and relationship among germplasm collections of radish, rice, sesame at morphological level ${ }^{10,1,5}$.

\section{Materials and Methods}

The present investigation was carried out at the Horticultural Research Farm of the Department of Applied Plant Science (Horticulture), Babasaheb Bhimrao Ambedkar University, Vidya Vihar, Rae Bareli Road, Lucknow (U. P.), India, during Kharif, 2013, in well leveled field having proper drainage. Geographically, Lucknow is situated at an elevation of $111 \mathrm{~m}$ above the mean sea level in the subtropical tract of Central Uttar Pradesh at $26^{\circ} 56^{\prime}$ North latitude and $80^{\circ} 52^{\prime}$ East longitude. The place experiences winter and very hot summer with average rainfall. Agro climatically, the location represent Central Zone of the state of Uttar Pradesh, India, and is characterized by sub-tropical climate. The experimental material comprising of 30 genotypes of cluster bean with row-row and plant-plant spacing were $45 \mathrm{~cm}$ and $30 \mathrm{~cm}$, respectively. All necessary cultural operations were done as and when required during the growing period. Data were recorded on 5 randomly selected plants per entry per replication for various characters namely, plant height $(\mathrm{cm})$, germination (\%), days taken for first flowering, days taken for $50 \%$ flowering, number of reproductive branches/plant, pod breath $(\mathrm{cm})$, pod length $(\mathrm{cm})$, pod width $(\mathrm{cm})$, number of pods/plant, number of pods /cluster, number of clusters /plant, number of branches /plant at maturity, number of seed /pod, pod yield /plant(g), pod yield/plot(kg), 100 seed weight $(\mathrm{g})$, seed yield/plant $(\mathrm{g})$, days to maturity and pod yield $(\mathrm{q} / \mathrm{ha})$. The mean values of five plants were taken for the analysis of genetic divergence following Mahalanobis ${ }^{6}$. Group constellation was performed according to the method suggested by Tocher; contribution of individual trait towards genetic divergence was quantified on the basis of coefficient of variation at genotypic and inter-cluster levels as described by Vavilov ${ }^{12}$.

\section{Results and Discussion}

The multivariate analysis $\left(\mathrm{D}^{2}\right)$ is a powerful tool to measure the genetic divergence within a set of genotypes ${ }^{7}$. The analysis of variance revealed significant differences among the genotypes for all the characters studied. The analysis of variance showed that significant differences among the genotypes for all 19 characters studied. The contribution of various traits to the genetic diversity worked out from their rank (Table 1). This suggested the presence of appreciable amount of diversity among the genotypes under study. The computed $\mathrm{D}^{2}$ values for 30 genotypes had wide range showing high divergence among the genotypes. Thirty genotypes were grouped into 5 clusters indicating large amount of genetic diversity among the genotypes (Table 2). The intra-cluster distance was ranged from 2.585-3.400 (Table 3). The computed $\mathrm{D}^{2}$ values for 30 genotypes had wide range showing high genetic divergence among the genotypes. The inter-cluster distance revealed that maximum divergence between cluster I and II $\left(D^{2}=7.016\right)$ closely followed by cluster II and V $\left(D^{2}=5.613\right)$, cluster II and III $\left(D^{2}=5.339\right)$, cluster I and IV $\left(D^{2}=4.841\right)$, cluster II and IV $\left(D^{2}=4.763\right)$ and cluster III and IV $\left(\mathrm{D}^{2}=4.337\right)$. The distance between cluster III and V $\left(D^{2}=3.450\right)$ was least. The maximum intra-cluster distance was found in cluster III $\left(D^{2}=3.400\right)$ closely followed by cluster V $\left(D^{2}=3.317\right)$ and Cluster IV $\left(D^{2}=3.081\right)$. The maximum and wide distance point out that selection of parents for hybridization programme is made from genetically diverse clusters (Table 3 ).

The maximum distances between clusters are the right choice of diverse parents for hybridization programme as suggested by Girish and Gasti et al. ${ }^{2}$, Rai and Dharmatti . The contribution of various traits to the genetic diversity worked out from their rank, maximum contribution (37.87\%) was from days to maturity followed by pod yield (22.32\%), seed yield per plant and least contribution of $0 \%$ from plant height and germination \% (Table 4). The mean value for all the characters are presented vide in (Table 4). Cluster IV had highest mean value for plant height $(95.50 \mathrm{~cm})$ and lowest value was from $(69.05 \mathrm{~cm})$ cluster II. The highest mean value for germination $\%$ was recorded by cluster III (92.43) and the lowest was recorded by Cluster I (89.37). Cluster III had the maximum mean value for day taken for first flowering (22.77) and the 
Table 1. Percent contribution of different characters of the total diversity in cluster bean genotypes

\begin{tabular}{llcc}
\hline S1. No. & Characters & $\begin{array}{c}\text { Number of } \\
\text { First Rank }\end{array}$ & $\begin{array}{c}\text { Contribution to } \\
\text { total divergence (\%) }\end{array}$ \\
\hline 1. & Plant height $(\mathrm{cm})$ & 0 & 0.00 \\
2. & Germination (\%) & 0 & 0.00 \\
3. & Days taken for first flowering & 15 & 1.51 \\
4. & Days taken for 50\% flowering & 12 & 1.21 \\
5. & Number of reproductive & 8 & 0.80 \\
& branches/plant & & \\
6. & Pod breath (cm) & 4 & 0.40 \\
7. & Pod length (cm) & 2 & 0.20 \\
8. & Pod width (cm) & 1 & 0.10 \\
9. & Number of pods/plant & 28 & 2.82 \\
10. & Number of pods /cluster & 20 & 2.02 \\
11. & Number of clusters /plant & 3 & 0.30 \\
12. & Number of branches /plant at & 15 & 1.51 \\
& maturity & & \\
13. & Number of seed /pod & 17 & 1.71 \\
14. & Pod yield /plant (g) & 35 & 3.53 \\
15. & Pod yield /plot (kg) & 5 & 0.50 \\
16. & 100 Seed weight (g) & 18 & 1.81 \\
17. & Seed yield /plant (g) & 215 & 21.71 \\
18. & Days to maturity & 375 & 37.87 \\
19. & Pod yield (q/ha) & 221 & 22.32 \\
& Total & 994 & 100.00 \\
\hline
\end{tabular}

Table 2. Grouping of cluster bean genotypes based on $\mathrm{D}^{2}$ values

\begin{tabular}{|c|c|c|c|}
\hline Sl. No. & Cluster No. & $\begin{array}{l}\text { Number of } \\
\text { individual/genotypes }\end{array}$ & Name of the genotypes \\
\hline 1. & I & 8 & $\begin{array}{l}\text { IC- } 258087 \text {, IC-258092, IC-369789, IC-369868, } \\
\text { IC-370490, IC-373427, IC-373480, IC-402293. }\end{array}$ \\
\hline 2. & II & 6 & $\begin{array}{l}\text { IC-421812, IC-421815, IC-421820, IC-421828, } \\
\text { IC-421834, IC-421838. }\end{array}$ \\
\hline 3. & III & 8 & $\begin{array}{l}\text { IC-370478, IC-415137, IC-415142, IC-415157, } \\
\text { IC-415159, IC-421242, IC-421798, IC-421806. }\end{array}$ \\
\hline 4. & IV & 3 & IC-421809, IC-421855, HG-365. \\
\hline 5. & V & 5 & $\begin{array}{l}\text { IC-28272, IC-311440, IC-311441, IC-325757, } \\
\text { IC-329038. }\end{array}$ \\
\hline
\end{tabular}

minimum was recorded by cluster V (20.73). The highest mean value was recorded for the character of days taken for $50 \%$ flowering from cluster II and the lowest value of 33.28 recorded form cluster III. Maximum number of reproductive branches per plant was observed from cluster III and minimum of 4.81 from cluster V. The highest mean value of $4.03 \mathrm{~cm}$ for pod breath was recorded in cluster V and lowest from cluster II and IV. Cluster I had maximum pod length, while cluster IV recorded minimum pod length. Cluster $\mathrm{V}$ recorded highest pod width with the mean value of 6.06 and cluster IV showed lowest of 5.80. Maximum number of pods per plant was recorded from cluster II (61.36) and lowest from cluster I (50.60). Cluster III took maximum pods per cluster (14.23) and cluster V was recorded with minimum (5.15). Maximum number of cluster per plant was recorded in the cluster of I and cluster IV was recorded minimum of 8.18. Cluster IV had highest mean values 
Table 3. Average intra and inter cluster $\mathrm{D}^{2}$ and $\mathrm{D}$ values of cluster bean genotypes

\begin{tabular}{lllllll}
\hline Sl. No. & $\begin{array}{l}\text { Cluster } \\
\text { Distances }\end{array}$ & Cluster I & Cluster II & Cluster III & Cluster IV & Cluster V \\
\hline 1. & Cluster I & $(2.585)$ & 7.016 & 4.280 & 4.841 & 3.752 \\
2. & Cluster II & & $(2.814)$ & 5.339 & 4.763 & 5.613 \\
3. & Cluster III & & $(3.400)$ & 4.337 & 3.450 \\
4. & Cluster IV & & & $(3.081)$ & 3.991 \\
5. & Cluster V & & & & $(3.317)$ \\
& & & & & 0.000 \\
\hline
\end{tabular}

Table 4. Cluster mean values for 19 biometrical characters in cluster bean genotypes

\begin{tabular}{|c|c|c|c|c|c|c|}
\hline Sl. No. & $7^{\text {Cluster }}$ & Cluster I & Cluster II & Cluster III & Cluster IV & Cluster V \\
\hline 1. & Plant height $(\mathrm{cm})$ & 77.55 & 69.05 & 87.38 & 95.50 & 76.12 \\
\hline 2. & Germination (\%) & 89.37 & 91.44 & 92.43 & 90.21 & 91.99 \\
\hline 3. & Days taken for first flowering & 22.56 & 22.13 & 22.77 & 21.96 & 20.73 \\
\hline 4. & Days taken for $50 \%$ flowering & 33.79 & 36.02 & 33.28 & 33.79 & 33.83 \\
\hline 5. & $\begin{array}{l}\text { Number of reproductive } \\
\text { branches/plant }\end{array}$ & 5.35 & 5.57 & 6.88 & 6.30 & 4.81 \\
\hline 6. & Pod breath $(\mathrm{cm})$ & 3.73 & 3.62 & 3.82 & 3.62 & 4.03 \\
\hline 7. & Pod length $(\mathrm{cm})$ & 5.88 & 5.68 & 5.86 & 5.29 & 5.57 \\
\hline 8. & Pod width $(\mathrm{cm})$ & 6.02 & 5.89 & 6.03 & 5.80 & 6.06 \\
\hline 9. & Number of pods/plant & 50.60 & 61.36 & 59.55 & 51.18 & 56.80 \\
\hline 10. & Number of pods / cluster & 5.88 & 5.84 & 14.23 & 5.26 & 5.15 \\
\hline 11. & Number of clusters / plant & 16.95 & 11.94 & 11.01 & 8.18 & 8.19 \\
\hline 12. & $\begin{array}{l}\text { Number of branches / plant at } \\
\text { maturity }\end{array}$ & 8.43 & 7.96 & 8.44 & 8.96 & 8.41 \\
\hline 13. & Number of seed /pod & 6.38 & 6.84 & 6.94 & 7.22 & 6.48 \\
\hline 14. & Pod yield /plant (g) & 90.00 & 111.05 & 94.18 & 117.85 & 84.27 \\
\hline 15. & Pod yield /plot $(\mathrm{kg})$ & 0.55 & 0.65 & 0.54 & 0.65 & 0.54 \\
\hline 16. & 100 Seed weight (g) & 3.65 & 3.39 & 3.62 & 4.08 & 3.40 \\
\hline 17. & Seed yield /plant (g) & 6.61 & 7.14 & 7.14 & 8.60 & 5.83 \\
\hline 18. & Days to maturity & 94.09 & 93.06 & 91.83 & 96.18 & 88.72 \\
\hline 19. & Pod yield (q/ha) & 125.22 & 133.15 & 125.10 & 138.85 & 123.66 \\
\hline
\end{tabular}

of number of per plant at maturity (8.96) and lowest was observed from cluster II (7.96). Cluster IV had maximum cluster mean values for number of seed per pod and minimum for Cluster I (6.38). Cluster IV had maximum cluster mean values for pod yield per plant (117.85 g) and minimum for Cluster V (84.27 g). Cluster II and IV had maximum cluster mean values for pod yield per plot $(0.65,0.65 \mathrm{~kg}$ each $)$ and minimum for Cluster III and V $(0.54,0.54 \mathrm{~kg}$ each). Cluster IV had maximum cluster mean values for 100 seed weight and minimum for Cluster II (3.39 g). Cluster IV had maximum cluster mean values for seed yield per plant and minimum for Cluster I (6.61g). Cluster IV had maximum cluster mean values for days to maturity and minimum for Cluster $\mathrm{V}$ (6.38). Cluster IV had maximum cluster mean values for pod yield and minimum for Cluster III (125.10 q). Cluster I and Cluster III was largest one with 8 genotypes each followed by cluster II, V and IV with 6,5 and 3 genotypes respectively (Table 4 ). Clustering between genetic diversity and geographical diversity are in accordance with Gipson and Balakrishnan ${ }^{3}$, Singh et al. ${ }^{11}$ and Pathak et al. ${ }^{8}$. 
Based on inter cluster distance and character with higher contribution to $\mathrm{D}^{2}$ values there is scope for varietal improvement through hybridization programme involving genotypes of cluster II with genotypes possessing desirable characters of cluster I (50\% flowering, clusters per plant, pods per cluster, pod yield per plant and yield per hectare) and cluster V (Number of pods per cluster and pods per plant). It was evident from the study that, there was considerable degree of variability for vegetable pod yield and its component characters. A few of the most promising genotypes for vegetable pod yield were IC258087, IC-258092, IC-369789, IC-369868, IC-370490, IC-373427, IC-373480, IC-402293, IC-370478, IC-415137, IC-415142, IC-415157, IC-415159, IC-421242, IC-421798 and IC-421806.

\section{Conclusion}

Ranking based on both mean performance and contribution of characters towards divergence resulted in the identification of IC- 258087, IC-258092, IC-369789, IC-369868, IC-370490, IC-373427, IC-373480, IC-402293, IC-370478, IC-415137, IC-415142, IC-415157, IC-415159, IC-421242, IC-421798 and IC-421806 as genotypes and can be utilized as parents in the hybridization programme for the improvement of pod yield and quality.

\section{References}

1. Akbar F, Rabbani MA, Shinwari ZK, Khan SJ. Genetic divergence in sesame (Sesamum indicum L.) landraces based on qualitative and quantitative traits. Pak. J. Bot. 2011; 43:2737-44.
2. Girish MH, Gasti VD et al. Genetic divergence studies in cluster bean genotypes [Cyamopsis tetragonoloba (L.) Taub.]. Karnataka Journal of Agricultural Sciences. 2012; 25(2):245-47.

3. Gipson A, Balakrishnan R. Genetic diversity in cluster bean. Indian J. Hort. 1992; 49(1):70-4.

4. Hymowitz T, Matlock RS. Guar in the United States. Oklahoma Agricultural Experiment Station Technical Bulletin. 1963; 611:1-34.

5. Jatoi SA, Javaid A, Iqbal M, Sayal OU, Masood MS, Siddiqui SU. Genetic diversity in radish germplasm for morphological traits and seed storage proteins. Pak. J. Bot. 2011; 43:2507-12.

6. Mahalanobis PC. On the generalized distance in statistics. Proceedings National Institute of Science, India. 1936; 2:49-55.

7. Murthy BR, Arunachalam V. The nature of genetic divergence in relation to breeding system in crop plants. Indian Journal of Genetics. 1966; 26:188-89.

8. Pathak R, Singh SK. Molecular assessment of genetic diversity in cluster bean (Cyamopsis tetragonoloba) genotypes. Journal of Genetics. 2010; 89(2):243-46.

9. Rai PS, Dharmatti PR. Genetic divergence studies in cluster bean genotypes [Cyamopsis tetragonoloba (L.) Taub.]. Global Journal of Science Frontier Research Agriculture and Veterinary. 2013; 13(5):45-8.

10. Siddiqui SU, Kummamaru T, Satoh H. Pakistan rice genetic resources-II: Distribution pattern of grain morphological diversity. Pak. J. Bot. 2007; 39:1533-38.

11. Singh UP, Tripati SN, Natarajan S. Guar Crop profile; 2009. Available from: http://www.igfri.res.in /crop_profile_guar. htm

12. Vavilov NI. The origin, variation, immunity and breeding of cultivated plants. Chronica Botanica. 1951; 13. 